\title{
Engineering Performance of Polyurethane Bonded Aggregates
}

\author{
Haimin WU*, Yiming SHU, Yunfeng LIU \\ College of Water Conservancy and Hydropower Engineering, Hohai University, Nanjing 210098, China \\ cross ${ }^{\text {ref }}$ http://dx.doi.org/10.5755/j01.ms.23.2.15798
}

\section{Received 26 July 2016; accepted 04 November 2016}

\begin{abstract}
In this paper the engineering performance of polyurethane (PUR) bonded aggregate were studied. The engineering performance, including compressive and flexural mechanical properties, void ratio, and coefficient of permeability were determined through laboratory tests. Moreover, the effects of two different curing conditions on the compressive strength properties of a PUR bonded aggregate were also evaluated. The compressive strengths of PUR bonded aggregates were found to be lower than that of conventional porous concrete, which is a commonly used cushion material. However, experimental results indicated a higher void ratio and coefficient of permeability, lower elasticity modulus, better toughness, and stronger adaptability to flexural deformation compared to porous concrete. Consequently, PUR bonded aggregate is a better solution than porous concrete when used as the cushion material of a geomembrane surface barrier for a high rock-fill dam.

Keywords: polyurethane bonded aggregate, permeability, compressive strength, elasticity modulus, flexural strength.
\end{abstract}

\section{INTRODUCTION}

The geomembrane surface barrier of a rock-fill dam is characterized by many advantages such as imperviousness, ease of construction and low cost $[1,2]$. Hence, this method has become the preferred solution for ensuring the water tightness of high rock-fill dams on thick pervious foundations in China. Due to the differential deformation of the surface of a dam slope, the lower cushion layer of a geomembrane barrier may yield to flexural failure and develop wide cracks, which pose a threat to the safety of the barrier under the long-term loading of high water pressure.

The two conventional cushion materials, namely granular materials and porous concrete, have been widely used for the support of geomembrane surface barriers for low rock-fill dams. For high rock-fill dams with a dam slope greater than 1:1.6, granular cushion materials are scarcely able to maintain stability [3]. Therefore, granular materials are not suitable for high rock-fill dams with steep slopes.

Porous concrete is an environmentally friendly concrete that has been widely used in many applications $[4,5]$. Numerous researchers have investigated the fundamental properties of conventional porous concrete [6-10]. In addition, higher strength applications of porous concrete have been developed by applying additives, optimizing the mixture ratio, or improving the construction procedure [11-15]. Furthermore, suitable porous concretes have also been developed using recycled aggregate along with optimum polymer contents [16]. The above literature has established that porous concrete is a good cushion material with good permeability and high strength. The material also has a coarse surface texture and can maintain its stability on the surface of dams with steep slopes [17]. However, porous concrete has also been found to exhibit a high elasticity modulus and an

\footnotetext{
* Corresponding author. Tel.: +86-25-83786883.

E-mail address: wuhaimin@hhu.edu.cn (H. Wu)
}

obviously brittle characteristic observed during compressive and flexural failure [18]. Therefore, when used as the cushion materials of geomembrane barriers for dams with steep slopes, flexural failure and the development of cracks can be expected due to its inability to resist flexural deformation at the surface of a dam slope.

Polyurethane bonded aggregate (PUR-BA) is a new elastic porous material made from a mixture of PUR adhesive and aggregate. When mixed in the proper ratio, PUR effectively bonds the aggregates into a firm and stable porous structure [19]. This new material promises good mechanical properties and satisfactory water permeability. Moreover, its final strength can be attained within a curing time of only two days. These characteristics indicate that PUR-BA may be a suitable alternative material for use as the cushion layer of geomembrane surface barriers for high rock-fill dams on thick pervious foundations.

The present research investigated the engineering performance of PUR-BA in the laboratory. The purpose was to examine the applicability of PUR-BA for use as the cushion layer of geomembrane surface barriers for high rock-fill dams. The optimum PUR content was firstly evaluated by a series of compressive strength tests with different mixture ratios. The effects of two extreme curing conditions on the mechanical properties of PUR-BA were also examined through compressive strength tests. On the basis of the compressive strength testing results, several laboratory experiments were conducted to investigate the flexural property, void ratio, and coefficient of permeability of the new material with the optimum PUR content. Then, the experimental results were compared with those properties of conventional porous concrete.

\section{EXPERIMENTAL}

\subsection{Materials}

According to the requirement for avoiding puncture, the particle size of a cushion material for a geomembrane 
surface barrier should be less than $20 \mathrm{~mm}$. In addition, to maintain a suitable void ratio and water permeability, the particle size of a cushion material is usually greater than $5 \mathrm{~mm}$ [20]. Therefore, crushed fresh basalt stones with particle sizes ranging from $5 \mathrm{~mm}$ to $20 \mathrm{~mm}$ were selected for the experiments. The physical properties of the aggregate are given in Table 1 . It should be noted that the aggregates were first washed and air-dried prior to testing.

The PUR used in the testing was obtained from BASF Polyurethane Specialties (China) Co., Ltd, which consists of components A and B, namely adhesive and catalyst, respectively. The properties of the two components of PUR are listed in Table 2.

\subsection{Specimen preparation}

The preparation of PUR-BA specimens was comprised of three steps.

Firstly, the PUR components A and B were mixed at a weight ratio of 1:0.65, and stirred until attaining a milky white color, as shown in Fig. 1.

Secondly, the well stirred mixture of PUR was mixed with aggregate according to the designated proportion. The PUR-aggregate mixture was stirred in a blender for a minimum of $20 \mathrm{~min}$.

Thirdly, the well stirred PUR-aggregate mixture was poured into molds of various shapes and sizes depending upon the test design. To facilitate later demolding, a releasing agent was brushed on the inside walls of molds prior to pouring. Most specimens were held at a temperature of $20 \pm 2{ }^{\circ} \mathrm{C}$ and a relative humidity of (R. H.) of $50-70 \%$ for $24 \mathrm{~h}$. After demolding, the samples were cured at room temperature for $24 \mathrm{~h}$, and then employed for testing. Photographs of the aggregate state prior to mixing and PUR-BA specimens are shown in Fig. 2.

It must be noted that the third specimen preparation step must be initiated within $30 \mathrm{~min}$ of beginning the first step to avoid hardening of the PUR adhesive prior to molding [19].

To obtain average values, three identical specimens were prepared for each test. The PUR-aggregate mixture exhibited good workability, and could be filled into spaces of virtually any size and shape. The specimen preparation method is very simple and required no special compaction, vibration, and curing conditions.

\subsection{Tests}

\subsubsection{Compressive strength test}

Compressive strength testing is one of the laboratory tests widely used in porous material applications, and is employed here as an important index to quantify the mechanical properties of the PUR-BA. The specimen used in compressive strength testing was cubic, with a uniform edge length of $100 \mathrm{~mm}$. A WEW-600B hydraulic universal testing machine was employed to apply a controlled compressive load. All compressive strength tests were conducted at a loading rate of $0.1 \mathrm{kN} / \mathrm{s}$. According to the results of preliminary research, the PUR content is generally between $1.0-2.0 \%$ for aggregates with a particle size of $5-20 \mathrm{~mm}$ [18].

Table 1. Properties of the aggregate

\begin{tabular}{|c|c|c|c|c|c|}
\hline $\begin{array}{c}\text { Range of particle } \\
\text { size, } \mathrm{mm}\end{array}$ & $\begin{array}{c}\text { Mean particle size } \\
\mathrm{D}_{50}, \mathrm{~mm}\end{array}$ & $\begin{array}{c}\text { Coefficient of } \\
\text { nonuniformity } \mathrm{C}_{\mathrm{u}}\end{array}$ & $\begin{array}{c}\text { Coefficient of } \\
\text { curvature } \mathrm{C}_{\mathrm{c}}\end{array}$ & $\begin{array}{c}\text { Unit weight, } \\
\mathrm{kg} / \mathrm{m}^{3}\end{array}$ & $\begin{array}{c}\text { Friction } \\
\text { angle, }\end{array}$ \\
\hline $5-20$ & 10 & 4.2 & 2.4 & 1725 & 48 \\
\hline
\end{tabular}

Table 2. Properties of the PUR

\begin{tabular}{|c|c|c|c|}
\hline Component & Appearance & Viscosity $\left(\mathrm{mPa} \cdot \mathrm{s}\right.$ at $\left.25^{\circ} \mathrm{C}\right)$ & Density $\left(\mathrm{kg} / \mathrm{m}^{3}\right.$ at $\left.25^{\circ} \mathrm{C}\right)$ \\
\hline $\mathrm{A}$ - adhesive & Canary yellow liquid & $2800 \pm 200$ & $1050 \pm 50$ \\
\hline $\mathrm{B}$ - catalyst & Brown liquid & $200 \pm 50$ & 1230 \\
\hline
\end{tabular}

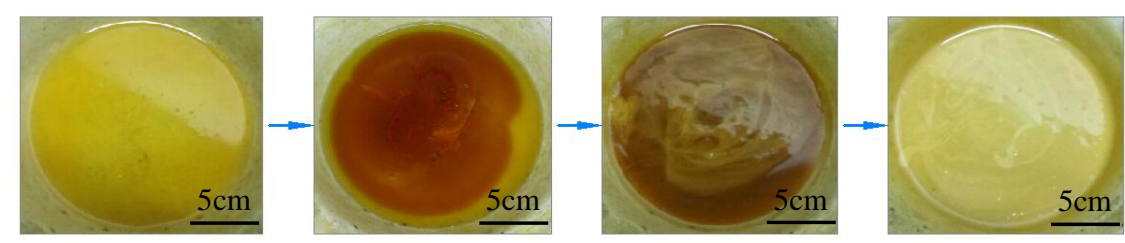

Fig. 1. Mixing process of PUR
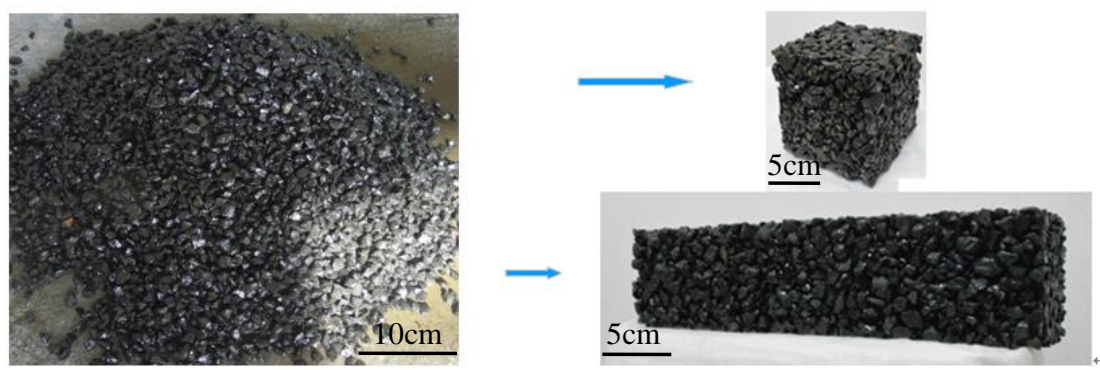

Fig. 2. The aggregate state prior to pouring and some PUR-BA specimens after demolding 
Therefore, five specimen groups with different PUR contents of $1.1 \%, 1.3 \%, 1.5 \%, 1.7 \%$, and $1.9 \%$ in increments of $0.2 \%$ by weight were used to investigate the effect of the PUR content on the compressive strength of the resulting PUR-BA.The optimum PUR content was then obtained by comparing the average compressive strengths of the specimen groups. In addition, to compare the effects of different curing conditions on the mechanical properties of PUR-BA, two additional specimen groups whose PUR content was set at the optimum content established from the above five tests were subjected to compressive strength testing, where one group was placed in a curing oven at $70 \pm 2{ }^{\circ} \mathrm{C}$, rather than being held at $20 \pm 2{ }^{\circ} \mathrm{C}$, for $24 \mathrm{~h}$, and the other group was immersed in room temperature water. Therefore, a total of 7 groups of compressive strength tests were conducted. Table 3 summarizes the experimental design of the compressive strength tests.

Table 3. Experimental design of the compressive strength tests

\begin{tabular}{|c|c|c|}
\hline Test number & PUR content, $\%$ & Curing condition \\
\hline 1 & 1.1 & $20 \pm 2{ }^{\circ} \mathrm{C}$ \\
\hline 2 & 1.3 & $20 \pm 2{ }^{\circ} \mathrm{C}$ \\
\hline 3 & 1.5 & $20 \pm 2{ }^{\circ} \mathrm{C}$ \\
\hline 4 & 1.7 & $20 \pm 2{ }^{\circ} \mathrm{C}$ \\
\hline 5 & 1.9 & $20 \pm 2^{\circ} \mathrm{C}$ \\
\hline 6 & Optimum content & $70 \pm 2^{\circ} \mathrm{C}$ \\
\hline 7 & Optimum content & $\begin{array}{c}\text { Immersed in water } \\
\left(20 \pm 2{ }^{\circ} \mathrm{C}\right)\end{array}$ \\
\hline
\end{tabular}

\subsubsection{Flexural property test}

The four-point flexural test method was employed to investigate the flexural properties of the PUR-BA [9]. The flexural test specimens were $400 \mathrm{~mm} \times 100 \mathrm{~mm} \times 100 \mathrm{~mm}$ sized cubic blocks. The PUR contents of all specimens were maintained at the optimum content obtained from the compressive strength tests. The flexural tests were also performed with the WEW-600B hydraulic universal testing machine at a loading rate of $0.1 \mathrm{kN} / \mathrm{s}$ applied in the $\mathrm{z}$-direction, as illustrated in Fig. 3.

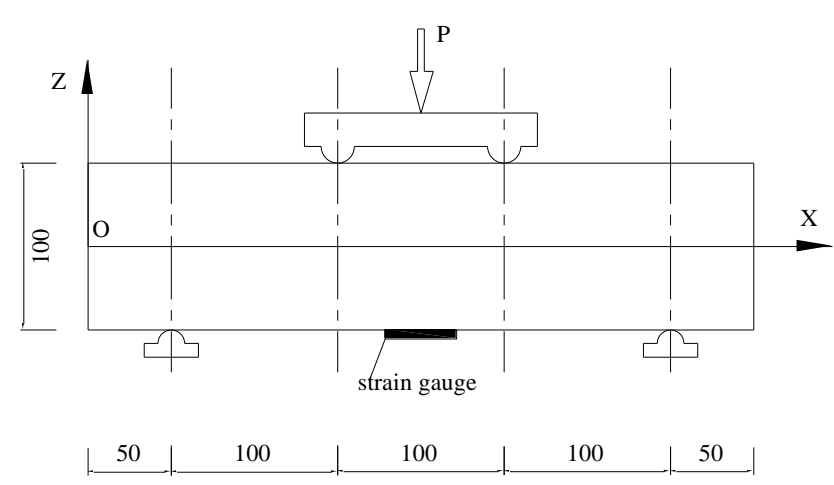

Fig. 3. Flexural property test (all dimensions in $\mathrm{mm}$ )

To help assess the ability of the PUR-BA to adapt to the flexural deformation of a dam surface, a stain gauge was mounted at the middle of the bottom face of the specimen to measure tension deformation during the flexural process. Additionally, a CCD camera was positioned at the side of the specimen along the $\mathrm{x}$ direction to record the flexural deformation process. A deflection curve was then plotted by means of postprocessing of the images captured by a CCD camera with measuring precision of $0.1 \mathrm{~mm}$.

\subsubsection{Void ratio and permeability tests}

The void ratio of the PUR-BA was tested by a weighting method [21]. The oven-dried specimens were first immersed in water for $24 \mathrm{~h}$. The initial mass $\left(M_{l}\right)$ of the specimen in the water was measured. Then, the final mass $\left(M_{2}\right)$ was measured after air-drying for $24 \mathrm{~h}$. The total volume of the specimen $(V)$, which includes the solid and void component, was calculated according to the geometry of the specimen. Then the void ratio of the PURBA specimen was calculated by Eq. 1:

$A(\%)=1-\left(\frac{\left(M_{2}-M_{1}\right) / \rho M}{V}\right) \times 100$,

where $\rho M$ is the density of water.

The coefficient of permeability of PUR-BA specimens was tested by the constant water head testing method [21]. A diagram of the permeability test is presented in Fig. 4. The specimen was a $\Phi 70 \mathrm{~mm} \times 100 \mathrm{~mm}$ cylinder. The specimen side wall was sealed by a tight cylindrical latex film to prevent leakage from the side-wall surface of the specimen. The two ends of the specimen were connected to a glass cylinder by steel flanges and seal rings. The water level difference $(H)$ was maintained at $40 \mathrm{~cm}$ during the test. Before testing, the air in the voids was fully discharged by immersing the specimen in water for $24 \mathrm{~h}$. The coefficient of permeability was calculated using the relationship given by Eq. 2 :

$k=\frac{L}{H} \times \frac{Q}{A \cdot \Delta t}$,

where $L, H, Q$, and $A$ are the apparatus dimensions defined by Fig. 4 , and $\Delta t$ is set as 10 seconds under a stable flow condition.

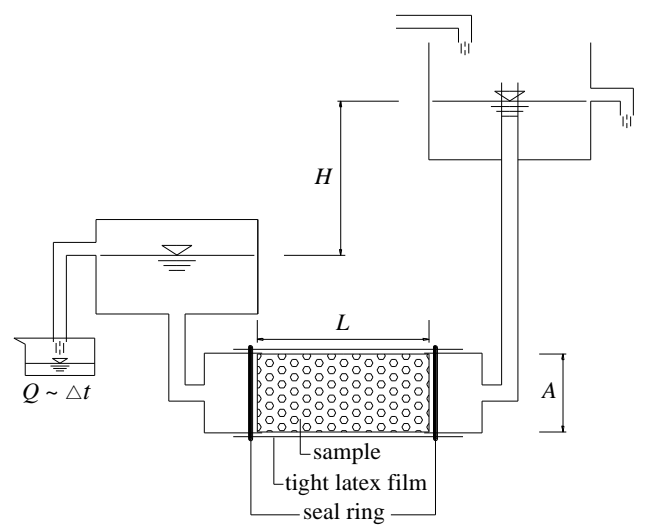

Fig. 4. Permeability test showing the dimensions used in Eq. 2

\section{RESULTS AND DISCUSSION}

\subsection{Compressive mechanical properties}

Fig. 5 shows the average compressive strengths of all PUR-BA specimens. The figure indicates that the compressive strength increases with increasing PUR 
content. This is assumed to be because PUR fills in the pores and enhances the rigidity of aggregates by forming a large number of rigid bonds connecting particles. However, the increase is slight when the PUR content exceeds $1.5 \%$. The reason for this greatly reduced increase may be owing to the trade-off between the enhancement of rigidity and the increasing thickness of the PUR film between aggregate particles. Therefore, the compressive strengths of specimens with PUR contents of $1.7 \%$ and $1.9 \%$ increase by only $3.02 \%$ and $4.69 \%$, respectively, relative to that of specimens with a PUR content of $1.5 \%$. As such, it is expected that a critical PUR content for the PUR-BA can hereby be determined. For the aggregate used in this test, $1.5 \%$ was selected as the optimum PUR content with the maximum cost performance. From the literature, it can be found that the compressive strengths of all PUR-BA specimens are lower than those of conventional porous concrete which $[17,18]$, where the compressive strengths of conventional porous concrete are typically greater than $10 \mathrm{MPa}$. However, the compressive strengths of the two materials can both meet the requirement of a cushion of geomembrane surface barrier for high rock-fill dams. Additionally, the effect of curing conditions on the compressive strengths of PURBA specimens is also shown in Fig. 5. It is evident that both of the extreme curing conditions have an influence on the compressive strength of the PUR-BA specimens.
Compared to the average compressive strength value obtained for specimens with an equivalent PUR content under the standard curing condition $\left(20 \pm 2{ }^{\circ} \mathrm{C}\right)$, the compressive strengths of specimens cured at $70 \pm 2{ }^{\circ} \mathrm{C}$ and those immersed in water at room temperature were reduced by $13.4 \%$ and $16.8 \%$, respectively. It is reasonable to assume that high temperature curing and immersion in water weaken the internal strength of the PUR, resulting in a decreased bonding force between aggregate particles.

Fig. 6 shows the average compressive stress-strain curves of specimens with different PUR contents under the three curing conditions. The compressive stress-strain results exhibit equivalent trends as those of the compressive strengths shown in Fig. 5, where the compressive stress increases with increasing PUR content, and both of the extreme curing conditions exhibit a definite decrease of compressive stress. For specimens with PUR content exceeding $1.5 \%$, the compression strains at peak stress are greater than $0.5 \%$.

The modulus of elasticity was calculated from the compressive stress-strain curves given in Fig. 6, which shows that the slopes of the curves generally increase with increasing PUR content, and the elastic modulus of the material is observed to increase from $0.29 \mathrm{GPa}$ to $0.81 \mathrm{GPa}$ when the PUR content increases from $1.1 \%$ to $1.5 \%$.

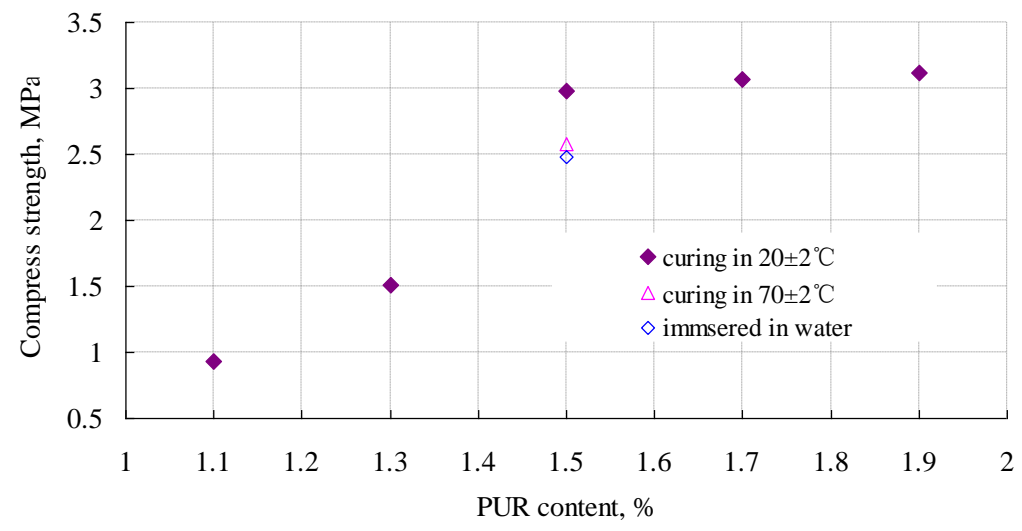

Fig. 5. Average compressive strengths of specimens with different PUR contents under various curing conditions

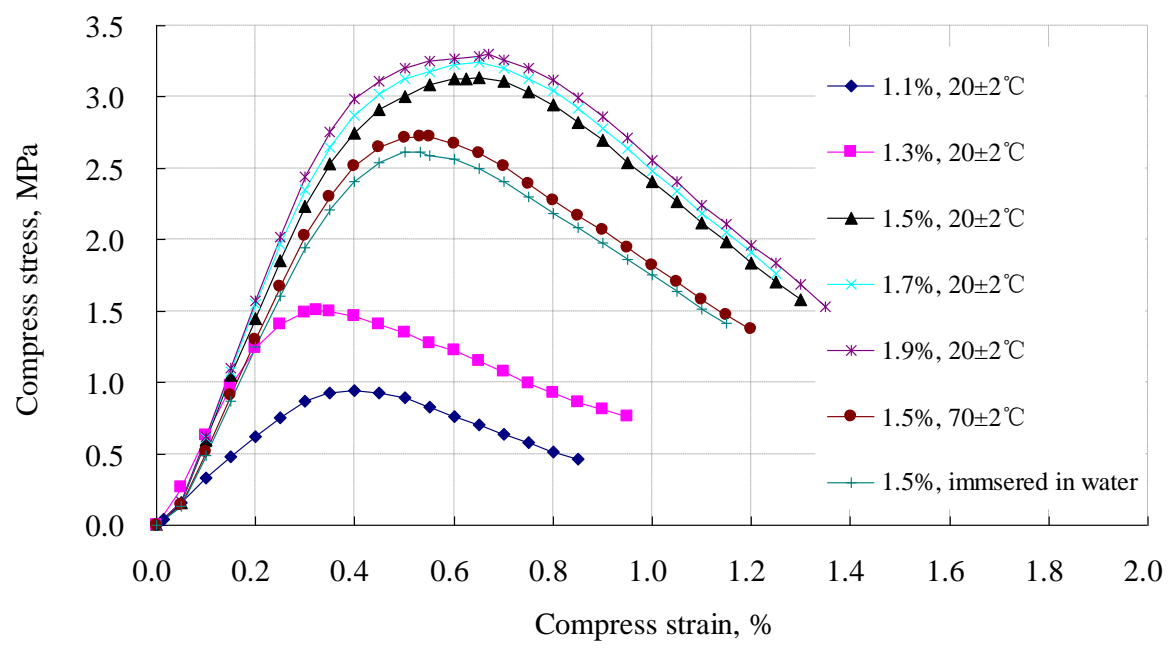

Fig. 6. Average compressive stress versus compressive strain of specimens with different PUR contents under various curing conditions 
When the PUR content exceeds $1.5 \%$, the trend weakens. It can be determined from the literature that the elastic modulus of the PUR-BA reported here is much lower than that of conventional porous concrete [22], where the elastic modulus of conventional porous concrete is typically in the range $20-30 \mathrm{GPa}$.

Fig. 7 shows the failure states of PUR-BA and porous concrete at peak compression. While the PUR-BA specimen presents an obvious ductile failure, only a few particles of the aggregate fall from the specimen after peak compression. However, porous concrete typically presents an obvious brittle failure [18]. The excellent toughness of PUR-BA may be expected to have a better ability to resist flexural deformation at the surface of a dam slope. So it can be indicated that the PUR-BA is more suitable to serve as a cushion layer of geomembrane surface barrier for high rock-fill dams.

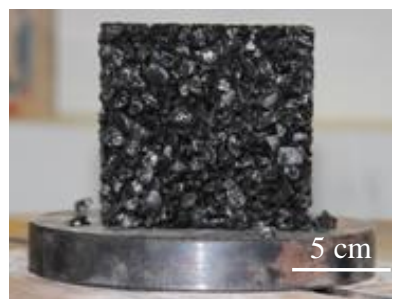

a PUR-BA

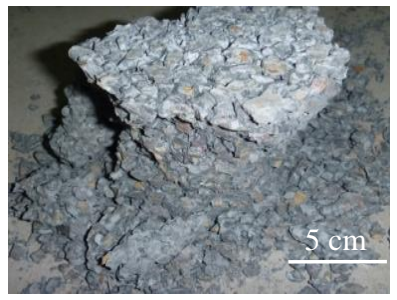

b porous concrete
Fig. 7. Failure states of specimens at peak compressions

\subsection{Flexural mechanical properties}

Fig. 8 shows a comparison of the average tension stress-strain curves based on strain gauge data obtained from the middle bottom of a PUR-BA specimen with a PUR content of $1.5 \%$ and the previously reported results for a conventional porous concrete specimen [22].

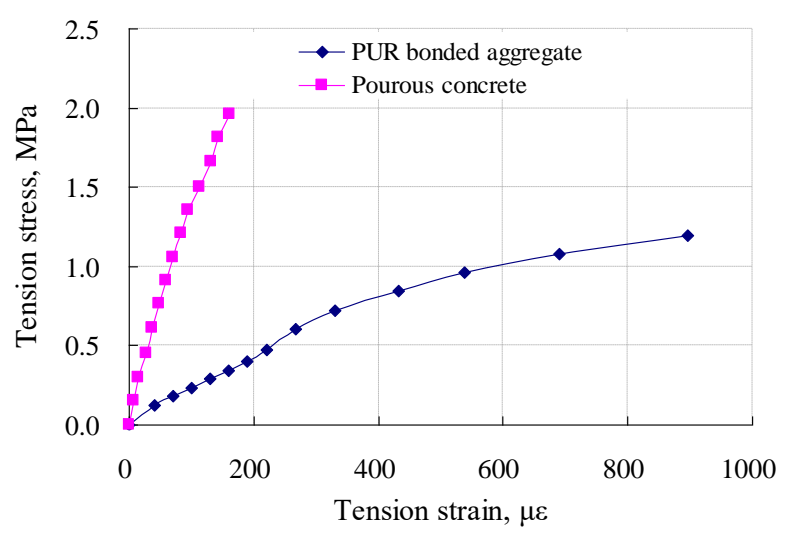

Fig. 8. Average tension stress-strain curves of optimum PUR-BA (PUR content of $1.5 \%$ ) and porous concrete in flexural tests

The maximum flexural strengths of the two materials are $1.2 \mathrm{MPa}$ and $2.25 \mathrm{MPa}$, respectively, and the corresponding maximum tension strains are $900 \mu \varepsilon$ and
$227 \mu \varepsilon$, respectively. The results indicate that the flexural strength of PUR-BA is only $53 \%$ as much as that of porous concrete. However, the tension strain at the failure point of PUR-BA is $396.5 \%$ as much as that of porous concrete.

The maximum deflection curves of the PUR-BA and porous concrete specimens measured by CCD camera are shown in Fig. 9 [22]. It can be observed that both curves present symmetrical distributions along the x-direction of the specimens (as described in Fig. 3). The maximum deflection values located at the middle of PUR-BA and porous concrete specimens are $1.86 \mathrm{~mm}$ and $1.2 \mathrm{~mm}$, respectively. In addition, the maximum ratios of deflection to span are $1 / 250$ and $1 / 161$, respectively. It can therefore be concluded that PUR-BA have better adaptability to flexural deformation then porous concrete.

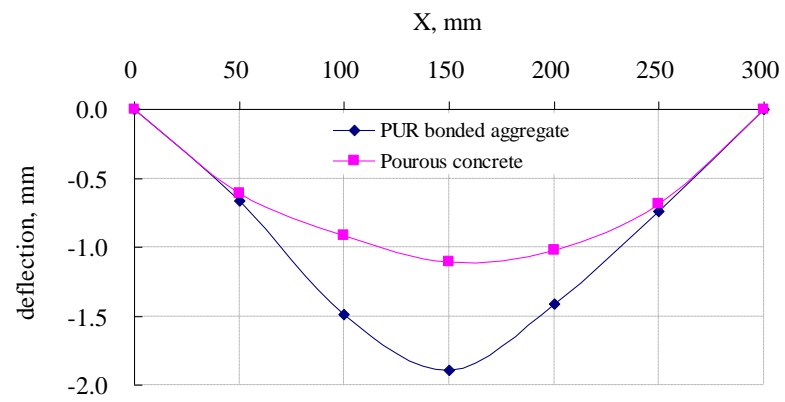

Fig. 9. Maximum deflection curves of the optimum PUR-BA (PUR content of $1.5 \%$ ) and porous concrete in flexural tests

\subsection{Void ratio and coefficient of permeability}

The void ratio and coefficient of permeability values of PUR-BA specimens with different PUR contents are listed in Table 4. The experimental results indicate that the PUR content has a negligible influence on the void ratio and coefficient of permeability. The reason for these findings could be that the PUR volume makes up only a very small portion of the total volume of the specimen about $3 \%$ or less.

As shown in Table 4, the void ratio and coefficient of permeability values of PUR-BA specimens with different PUR contents are greater than $30 \%$ and $7 \mathrm{~cm} / \mathrm{s}$, respectively, which are both higher than the corresponding values for porous concrete [22], where void ratio and coefficient of permeability values of conventional porous concrete is typically lower than $30 \%$ and $0.3 \mathrm{~cm} / \mathrm{s}$, respectively. According to previous studies, permeable materials for which the coefficient of permeability is greater than $0.1 \mathrm{~cm} / \mathrm{s}$ should be selected as the cushion layer of geomembrane surface barriers for dams [23]. Therefore, PUR-BA can completely satisfy the requirements of water permeability when used as the cushion layer of geomembrane surface barriers for high rock-fill dams.

Table 4. Void ratio and coefficient of permeability values of PUR-BA

\begin{tabular}{|c|c|c|c|c|c|}
\hline PUR content & $1.1 \%$ & $1.3 \%$ & $1.5 \%$ & $1.7 \%$ & $1.9 \%$ \\
\hline Porosity, $\%$ & 35.5 & 35.1 & 34.8 & 34.4 & 33.9 \\
\hline Permeability coefficient, $\mathrm{cm} / \mathrm{s}^{-1}$ & 7.9 & 7.7 & 7.6 & 7.6 & 7.5 \\
\hline
\end{tabular}




\section{CONCLUSIONS}

The compressive strengths of PUR-BA increase with increasing PUR content until attaining a critical PUR content, which is selected as the optimum PUR content. Curing conditions such as high temperature curing or immersion in water resulted in a definite decrease in the compressive strengths of PUR-BA.

The elasticity modulus of the optimum PUR-BA was only $1 / 20$ as much as that of conventional porous concrete. The PUR-BA demonstrated an obvious ductile failure, but not brittle failure such as that demonstrated by porous concrete.

The flexural strength of the optimum PUR-BA is much lower than that of conventional porous concrete. However, the tension strain at the failure point of the PUR-BA is three times as much as that of conventional porous concrete. The value of the maximum relative flexural deflection of the optimum PUR-BA specimen attained a value $1 / 250$ versus $1 / 161$ for porous concrete. The PURBA therefore demonstrated a better adaptability to flexural deformation than conventional porous concrete.

The void ratio and coefficient of permeability of the optimum PUR-BA are greater than $30 \%$ and $7 \mathrm{~cm} / \mathrm{s}$, respectively, which were both higher than those of conventional porous concrete.

Although the tested compressive and flexural strengths of PUR-BA were lower than those of conventional porous concrete, the PUR-BA exhibited a higher void ratio and coefficient of permeability, lower elasticity modulus, better toughness, and stronger adaptability to flexural deformation compared to conventional porous concrete. As such, this material can be a better solution using as the cushion layer of geomembrane surface barriers for high rock-fill dams on thick pervious foundations.

\section{Acknowledgments}

The present research was financially funded by the CRSRI Open Research Program (No. CKWV2015210/KY), Natural Science Foundation of China (Nos. 51409083 and 51379069), the Fundamental Research Funds for the Central Universities (No. 2016B00214) and the Priority Academic Program Development of Jiangsu Higher Education Institutions. Authors would like to thank the anonymous referees whose comments helped us improve the presentation of this research.

\section{REFERENCES}

1. ICOLD, the International Commission on Large Dams. Bulletin 135. Geomembrane Sealing Systems for DamsDesign Principles and Return of Experience, Paris, France, 2010: pp. $13-15$.

2. Cazzuffi, D., Giroud, J.P., Scuero, A., Vaschetti, G. Geosynthetic Barriers Systems for Dams Proceedings of 9th International Conference on Geosynthetics 2010: pp. $1265-1268$.

3. Wu, H., Shu, Y. Stability of Geomembrane Surface Barrier of Earth Dam Considering Strain-Softening Characteristics of Geosynthetic Interface KSCE Journal of Civil Engineering 16 (7) 2012: pp. 1123-1131.
4. Beecham, S. Water Sensitive Urban Design, a Technological Assessment. Waterfall Journal Stormwater Industry Association 17 2003: pp. 5-13.

5. Tennis P.D., Leming, M.L., Akers, D.J. Pervious Concrete Pavements, EB302.02, Portland Cement Association, Skokie, Illinois, and National Ready Mixed Concrete Association, Silver Spring, Maryland, USA, 2004: pp. 136.

6. Fujiwara, H., Tomita, R, Okamoto, T., Dozono, A, Okabe, A. Properties of High-Strength Porous Concrete ACI SP179, 1998.

7. Yang, J., Jiang, G. Experimental Study on Properties of Pervious Concrete Pavement Materials Cement and Concrete Research 33 2003: pp. 381-386.

8. Crouch, P.E., Pitt, J., Hewitt, R. Aggregate Effects on Pervious Portland Cement Concrete Static Modulus of Elasticity Journal of Materials in Civil Engineering 19 (7) 2007: pp. $561-568$.

9. Wu, H., Huang, B., Shu, X., Dong, Q. Laboratory Evaluation of Abrasion Resistance of Portland Cement Pervious Concrete Journal of Materials in Civil Engineering 23 (5) 2010: pp. 697-702.

10. Shu, X., Huang, B., Wu, H., Dong, Q., Burdette, E.G. Performance Comparison of Laboratory and Field Produced Pervious Concrete Mixtures Construction and Building Materials 25 (8) 2011: pp.3187-3192.

11. Chindaprasirt, P., Hatanaka, S., Chareerat, T., Mishima, N., Yuasa, Y. Cement Paste Characteristics and Porous Concrete Properties Construction and Building Materials 22 2008: pp. 894-901.

12. Huang, B, Wu, H., Shu, X., Burdette, E.G., Laboratory Evaluation of Permeability and Strength of PolymerModified Pervious Concrete Construction and Building Materials 24 (5) 2010: pp. 818-823.

https://doi.org/10.1016/j.conbuildmat.2009.10.025

13. Lian, C., Zhuge, Y. Optimum Mix Design of Enhanced Permeable Concrete-An Experimental

Investigation Construction and Building Materials 24 2010: pp. 2664-2671.

https://doi.org/10.1016/j.conbuildmat.2010.04.057

14. Hatanaka, S., Mishima, N., Maegawa, A., Sakamoto, E. Fundamental Study on Properties of Small Particle Size Porous Concrete Journal of Advanced Concrete Technology 12 2014: pp. 24-33. https://doi.org/10.1016/j.conbuildmat.2011.12.024

15. Aamer Rafique Bhutta, M., Tsuruta, K., Mirza, J. Evaluation of High-Performance Porous Concrete Properties Construction and Building Materials 31 2012: pp. 67-73.

16. Aamer Rafique Bhutta, M., Hasanah, N., Nur Farhayu, M.W.H., Mahmood bin Md Tahir, J.M. Properties of Porous Concrete from Waste Crushed Concrete (Recycled Aggregate) Construction and Building Materials 47 2013: pp. $1243-1248$. https://doi.org/10.1016/j.conbuildmat.2013.06.022

17. Teng, Z., Shu, Y., Wu, H., Dai, L. Study of Test on Mixed Proportions Design and Mechanical Properties of No Fines Concrete Cushion Layer YELLOW RIVER 34 (10) 2012: pp. 139-141 (in Chinese).

18. Wu, H.M. Research on Key Problems in Geomembrane Surface Barrier of Rock-fill Dam on Thick Riverbed Alluvial Deposit Ph.D. Dissertation, Hohai University, Nanjing, China, 2013 (in Chinese).

19. Gu, D., Verhagen, H.J., Van de Ven, M. Preliminary Study f Pur-Revetment's Application [OL]. 2008. 02. 19. 
SciencePaperOline

(http://www.paper.edu.cn/html/releasepaper/2008/02/178/) (in Chinese).

20. The Compiling Commission of Engineering Application Manual of Geosynthetic. Engineering Application Manual of Geosynthetic. China Architecture and Building Press, Beijing, 2000: pp. 128 - 129 (in Chinese).

21. Tamai, M., Mizuguchi, H., Hatanaka, S., Katahira, H., Nakazawa, T., Yanagibashi, K., Kunieda, M. Design, construction and recent applications of porous concrete in Japan[C]//Proceedings of the JCI symposium on design, construction and recent applications of porous concrete, Japan Concrete, Institute, Tokyo; 2004: pp. 1 - 10.
22. Teng, Z. Engineering Characteristic Study on Non-particle Cushion Layer in Geomembrane Anti-seepage Structure of Higher Rock-fill Dam. Master Dissertation, Hohai University, Nanjing, China, 2013 (in Chinese).

23. Jayawickrama, P., Brown, K., Thomas, J., Lytton, R. Leakage Rate Through Flaws in Geomembrane Liners Journal of Environmental Engineering ASCE $114(6)$ 1988: pp. $1401-1420$.

https://doi.org/10.1061/(ASCE)0733-

9372(1988)114:6(1401) 